\title{
Religious feeling and its influence on the level of moral consciousness of modern student youth
}

\author{
Irina Sokolovskaya ${ }^{1, *}$ \\ ${ }^{1}$ Russian State Social University, Russia
}

\begin{abstract}
An important task of the society is to develop the moral consciousness of the student youth, since it is they who will further build our country, using concepts based on historical experience about good and evil, justice, honor and dignity. This task is solved using, among other things, the means of science, namely philosophy, ethics, sociology and ecology. At the same time, attempts to look at this topic from the standpoint of psychological science are still relatively rare. Studies of the influence of religiosity on the general moral state of young people are particularly sparse, which leads to the lack of any precisely formulated and justified criteria in the modern understanding of the problem. This position forms, in fact, the task for the psychologist: to identify the structure of moral consciousness typical for a representative of a modern student, to determine the necessary stages and means for the process of moral maturation of a young person receiving higher education. It is particularly important to determine the relationship between personal religious feelings and the formation of mature moral qualities in the student's psychotype. Studying the works of psychologists who laid the foundations for understanding the processes of moral and spiritual development of the individual, we can imagine the stages of studying a particular process that interests us - from the formulation of a hypothesis to the selection of diagnostic techniques and methods of mathematical processing of results. Without any doubt, the field of view of the study included the definition of value and life-meaning orientations of students, which is ultimately and most important for everyone who takes part in the formation and education of young builders of the future life of our society.
\end{abstract}

\section{Introduction}

Modern students will have to live and develop our country in the conditions of artificial intelligence. Of course, we, the representatives of the older generation, who pass the torch of further development of society along the path of progress, would like the current young generation not to contribute to the disappearance of such categories as civic duty, the meaning of life, moral principles, in short, everything that makes up the public idea of a worthy member of society. In fact, the spiritual maturity of young people is one of the foundations of the country's economic, political, and cultural achievements, and is thus the most urgent task of development and progress.

\footnotetext{
*Corresponding author: iesokol@yandex.ru
} 
I would like to emphasize that in the works that have appeared in recent years, the topic of moral consciousness of young people is studied in philosophical, ethical, environmental and sociological aspects (Melnik N. and others [1], Yan Wang and others [2]), Shepherd J.[3], Kostruba N. [4]; in the psychological aspect, the following works are interested: Linchenko A.[5], Manolov, M.[6], Revushkina M. B.[7], Nikolaeva I., Ovcharova R.[8], Yachina N. [9], Ara, R., \& Mahjabeen, T. [10], Sokolovskaya I. E.[11,12,13]; in foreign literature, the following works on moral consciousness can be noted: Adriana Denisa Manea [14], Tina Lindhard [15], Eren Can Aybek, Duygu Çavdar, Tansu Mutlu Nilüfer Özabacı [16], Natalya Khon, Alla Kim [17], Oliver Scott Curry, Matthew Jones Chesters, Caspar J. Van Lissa [18]. However, in the context of psychological approaches that interest us, the influence of religious feeling on the level of moral consciousness of young people, there are very few modern works, and they are devoted not to the problems of moral consciousness development, but mostly to the development of personality. Religious feeling and its influence on the level of moral consciousness of modern students of the Russian State Social University was studied in 2020 by me and my master's student A.V. Groshova, with the results of which we will introduce you in this paper.

In general, the review of scientific works made it possible to conclude that there are no established views on the content and structure of moral consciousness, its specific features are not characterized, and the interaction of social, pedagogical, and psychological factors in the dynamics of maturation of the moral consciousness of an individual, in particular, of student youth, is not highlighted. This understanding of the unsolved problem, both in theoretical and experimental aspects, formed the basis of our research.

As the theoretical review of the literature has shown, the moral consciousness represented in the mental structure of the student's personality affects all his moral behavior. At the same time, the criteria for the development of a person's moral consciousness are the following: a sufficiently high moral ideal (not lower than the requirements of the natural moral law), which ensures the absence of deep internal conflicts with conscience; a moral consciousness that forms sensitivity to situations of moral choice.

In our opinion, there is a relationship between personal factors, religious feeling and the level of development of moral consciousness of student youth.

A variety of theoretical and experimental methods for studying the moral consciousness of the individual characterizes the current state of psychological science. This situation occurs because of the many directions of modern psychological teachings, and not least because of the complexity of the object. As a result of this state of affairs, the very understanding of the term "moral consciousness" varies in meaning and is interpreted differently in various sources. There are also definitions of morality based on philosophical concepts: 1) conventionalism; 2) utilitarianism; 3) absolutism (absolutely autonomous; absolutely heteronomous; intuitive theories); 4) naturalism (classical naturalism; neonaturalism; psychological understanding of morality; evolutionary ethics); 5) cosmism; 6) sociological justification of morality.

According to the postulate accepted by modern psychological science, consciousness is determined by the psyche and is, in fact, its highest form, which, in turn, is the product of the individual's life activity in its social and historical relationships, work, communication verbal and otherwise - with other members of the society.

Deeping the analysis of various scientific views on moral consciousness, we will turn to foreign psychology, especially since it has a special area - the psychology of morality. Let's start with psychoanalysis of Z. Freud. Z. Freud argued that for the normal functioning of a person in society, the person must have a set of norms that coincide with those accepted in this society. These norms for the individual are the formed ego - ideals, the ultimate goal of the formation of the "superego". 
Continuing interest of Z. Freud to the problems of the relationship between morality and consciousness, neo-Freudian scientists, unlike their great predecessor, shifted their focus from the biological to the social and cultural background of certain human actions. For example, E. Fromm's "humane ethics of self-realization" proceeds from the premise of a person as a carrier of moral criteria, reflected in his formulation that the character structure of a mature and productive person is itself a source of "virtue", and that "evil" is indifference to oneself and self-destruction.

Consequently, according to E. Fromm, the moral progress of the individual is adequate to the development of the individual. Thus, the scientist understands the moral development of a person as the development of his individuality and considers this personal process to be virtuous and creative.

Tina Lindhard hypothesized that the principle of life of the Universe is a great cosmic game of two opposite poles, in which it is possible to identify the male and female principles, the polarity referred to by Chinese philosophy as Yin-Yang. The scientist also formed her own image of the Universe, where there is a force that causes all particles to pulsate and there is a kind of conscious mind that is embodied in continuously changing forms. This basic cosmological principle can be felt by animals and people, especially those who live close to nature, and not in modern cities that suppress consciousness. Developing Haeckel's theory in the part where the phylogenetic process can reflect the ontogenesis of nature, Tina Lindhard formulates the idea of nature as a living organism, a single whole, continuously fertilized by a creative pulsating force. We believe that these assumptions may have theological and cosmological significance. [15].

The thought of V. Frankl is valuable for our work, who believed that one of the indicators of the moral level is the ability of an individual to implement free will in his life, while it is important to be able to listen to their conscience and to take responsibility for their own fate, the result of this attitude a person decides for themselves, the decision for myself - always shaping yourself.

In the course of personal development, there is a kind of accumulation of its moral wealth, this property of the individual passes to higher levels, that is, the inner sphere itself already exists as an initiator of personal development. This is the moral progress of the individual, the personal movement towards inner perfection.

Consciousness is something for obtaining knowledge about what is outside the individual, information about the World and its place in it. Thanks to self-awareness, an individual can orient himself, his soul and feelings, and feels himself.

\section{Materials and methods}

The work on identifying the relationship between religious feelings and the level of moral consciousness of student youth was carried out at the Russian State Social University (Moscow. Russia).

The sample consisted of 250 student youth, young men and women aged 19 to 25 years, with diverse degrees of development of moral knowledge and skills in the family and school, different characters, which makes this research task difficult to solve and heterogeneous in results.

Moral thinking, this continuously operating "controller of morality", personally acquired moral principles, is the morality of the individual. The moral triad - feelings, consciousness, and thinking - is the foundation of the moral will. Without moral will and an active attitude to life, society, there is no real moral personality.

Therefore, the hypothesis of the study was the following natural connection: moral consciousness is the area of thinking of the individual, included in the moral sphere, dynamically applied by the individual in relations with society, in the awareness of their 
behavior, so the absence or presence of religious feelings, or the presence of the will that keeps students from committing immoral acts depends on the developed thinking, will and moral consciousness.

To achieve this goal and achieve the designated tasks, special diagnostic methods were selected: the method of prototypical analysis according to P. Verges of the social representation of "morality" [19]. Methods for studying the relationship between the characteristics of moral consciousness and other personal characteristics of students: questionnaire of life-meaning orientations in the adaptation of D. A. Leontiev (LMO) [20]; Methods for determining the types of coping strategies of R. Lazarus [21]; Methods for diagnosing moral characteristics of the individual and the level of its psycho-ethical development (A.V. Sukhih, N. I. Korytchenkova) [22]; Methods of quantitative and qualitative analysis of psychological research data are used as methods of mathematical processing of experimental data.

\section{Result}

To identify the level of moral consciousness of students, two samples of respondents were examined: 1) students of the 2nd year of the master's degree of psychology faculty of the RSSU (average age 23-25 years); 2) students of the 4th year of the specialist of the psychological faculty aged 22-23 years.

With the help of the author's questionnaire "My attitude to religion", the attitude to religious moral and ethical attitudes of students was revealed. The total sample (250 people) was differentiated into three experimental groups based on the degree of religious feeling.

Group 1 - high level of moral attitudes (true religious students) - 60-90 points;

Group 2 - average level of moral attitudes (formally religious students) - 30-59 points;

Group 3 - low level of moral attitudes (non - religious students) - 0-29 points.

According to the results of the diagnosis, the first group was 50 people $-20 \%$ of the total number of interviewed students; the second -150 people $-60 \%$ and the third group was 50 people $-20 \%$.

Thus, the largest group was the group of interviewed students with an average level of moral attitudes (formally religious students), for whom the understanding of faith, morality and morals was either the result of family upbringing, or national and cultural affiliation, the desire to follow the traditions of their ancestors. This is a kind of "external" religiosity, without interiorization of the faith. Motivations to adhere to moral attitudes had nothing to do with religious faith and the need to communicate with Higher forces, they were pragmatic, social in nature (for the company with friends; everyone went, and I went), in order to achieve personal goals (to pray for themselves and their loved ones, put a candle on good luck, etc.), or simply because they consider themselves believers who are required to attend Church, because "everyone does it". The group with high moral attitudes (true religious students), observing moral attitudes, was dominated by the need to communicate with God, the desire to know God and Divine truths, and an emotionally saturated attitude to religion and the Church. In the group with low moral attitudes (non-religious students), who do not associate moral attitudes with religion and do not adhere to them, there was an emphasis on self-love and freedom of choice.

The analysis of students' social views to the perception of morality was carried out using the method of P. Verges, which reveals the structures of views. Only those concepts that were reproduced by at least $5 \%$ of the interviewed students were examined. This method allows us to identify and examine the structure of the view of "morality" through the procedure of prototypical analysis. 
Table 1. Results of prototypical analysis according to P. Verges of the social view of "morality".

\begin{tabular}{|c|c|c|c|c|}
\hline & $\begin{array}{c}\text { The high level of } \\
\text { morality (HLM) }\end{array}$ & $\begin{array}{c}\text { The average level of } \\
\text { morality (ALM) }\end{array}$ & $\begin{array}{c}\text { The low level of } \\
\text { morality (LLM) }\end{array}$ & $\begin{array}{c}\text { Whole } \\
\text { sample }\end{array}$ \\
\hline Core area & $10.2 \%$ & $36 \%$ & $14 \%$ & $20.06 \%$ \\
\hline Associations & Faith & Faith, well-mannered & Religion & $13.26 \%$ \\
\hline $\begin{array}{c}\text { Area of the } \\
\text { periphery }\end{array}$ & $9.8 \%$ & $24 \%$ & $6 \%$ & \\
\hline $\begin{array}{c}\text { Associations } \\
\text { Total }\end{array}$ & $\begin{array}{c}\text { Morality, honesty, } \\
\text { joy }\end{array}$ & $\begin{array}{c}\text { Obedient, tradition, } \\
\text { spiritual }\end{array}$ & $\begin{array}{c}\text { Aggressive, alien, } \\
\text { excessive }\end{array}$ & \\
\hline $20 \%$ & $60 \%$ & $20 \%$ & $33.3 \%$ \\
\hline
\end{tabular}

In the case of the word "morality", the proportion of core area and periphery area elements for the whole sample is approximately $33.3 \%$ of all associations $(20.06 \%$ - core and $13.26 \%$ - periphery):

1) "Core" (average rank < 4, average frequency of association $>20$ ) - associations "faith", "well-mannered", "religion".

2) "Periphery": zone of potential changes (average rank $<4$, average frequency of association $<20$ or average rank $>4$, average frequency of association $\geq 20$ ) - associations "morality", "honesty", “obedient", "tradition", "aggressiveness";

3) "Actually periphery" (average rank $>4$, average frequency of association $<20$ ) associations "joy", "spiritual", "alien", "excessive".

If the proportion of the core and periphery of social views in students with a low level of morality (LLM) and students with a high level of morality (HLM) does not statistically differ $\left(\mathrm{T}=1.243\right.$ at the $\left.\mathrm{T}_{\mathrm{Tab}}=2.8707\right)$, then the content at the core level has a clear tendency to determine morality from the external in students (LLM) to the internal in students (HLM) $\left(\mathrm{T}=3.345 \mathrm{p}<0.01\right.$ at the $\left.\mathrm{T}_{\mathrm{Tab}}=2.8707\right)$. The periphery shows a high potential for overcoming (adaptive potential) among students (HLM) and denying the possibility of using it among students (LLM).

The purpose of the next empirical study was to analyze the value conditioning of the moral worldview and the influence of moral self-awareness on the choice of students' value and life-meaning orientations. In the comparative study, the total sample was divided into groups of moral/morally unstable due to the questionnaire "My attitude to religion". The test of D. A. Leontiev's of life-meaning orientations, a structured psychological interview including worldview questions, was used (table 2). At the stage of mathematical processing of the obtained empirical data, the Student's t-test was used.

Table 2. Results of the analysis of the test of life-meaning orientations by D. A. Leontiev.

\begin{tabular}{|c|c|c|c|c|}
\hline Scales & Moral & Morally unstable & t-test & Significance level \\
\hline 1. Goals & 32.80 & 31.00 & 0.800 & \\
\hline 2.Process & 29.30 & 40.34 & 3.451 & $\mathrm{p} \leq 0.005$ \\
\hline 3.Result & 38.43 & 26.24 & 2.617 & $\mathrm{p} \leq 0.05$ \\
\hline 4. Locus of control - I & 21.45 & 21.70 & 0.288 & \\
\hline 5. Locus of control - life & 32.36 & 32.56 & 0.479 & \\
\hline
\end{tabular}




\begin{tabular}{|l|l|l|l|l|}
\hline 6. The meaning of life & 108.23 & 107.56 & 0.068 & \\
\hline
\end{tabular}

The analysis of students' value orientations showed that there is a differentiation of students by value orientations, and there are differences between moral and morally unstable ones. The most common phenomenon in the student environment - individualism of the pragmatic type - is more inherent in morally unstable students. The author reveals the polarization of personality types that are the real basis for creating conflict situations in higher educational institution, in the relations between moral and non-moral students.

On the scale of "Goals in life" (32.8 for moral students), they characterize the presence of goals in the life of the interviewed student in the future, which give life meaning, direction and time perspective. According to the "Process of life" scale (40.34 for morally unstable students), it indicates the interest and emotional saturation of life. For these students, the only meaning of life is to live, and therefore they like the process of life itself as filled with meaning. On the scale of "Life result" (38.43 for moral students) indicate satisfaction with self-realization in these students. On the scale of "Locus of control - I' (I am the master of life) (21.45 for moral students) indicate that moral students do not have faith in their own power to control its events, they tend to rely on the will of God and that their life is in His hands. Morally unstable students have higher scores (21.70) on this scale and correspond to their self-image as a strong personality. On the "Locus of control - life" scale, or manageability of life (32.56 for morally unstable students), high scores indicate that these students believe that a person is given control of their life, freely make decisions and implement them. Moral students have scores somewhat lower (32.36), and point out the fatalism.

Further, the study of the relationship between the attitudes of the moral orientation of students' consciousness and the properties of personality was carried out using the "Methodology for determining the types of coping strategies of R. Lazarus". Indicators of coping mechanisms, ways to overcome difficulties in various areas of mental activity, and coping strategies were calculated. The higher this indicator is for students, the less, in our opinion, stable their moral attitudes are, and the lower their moral orientation.

Table 3 shows the average indicators characterizing the moral orientation of consciousness and coping strategy of students-psychologists.

Table 3. Average indicators that characterize the moral sphere and coping strategies of students' personality.

\begin{tabular}{|c|c|c|c|c|}
\hline Coping strategies & Moral & $\begin{array}{c}\text { Morally } \\
\text { unstable }\end{array}$ & t-test & $\begin{array}{c}\text { Significance } \\
\text { level }\end{array}$ \\
\hline Confrontation & 27.15 & 45.50 & 4.812 & $\mathrm{p} \leq 0.005$ \\
\hline Distancing & 35.7 & 28.55 & 0.479 & \\
\hline Self-control & 45.34 & 21.45 & 4.617 & $\mathrm{p} \leq 0.005$ \\
\hline Search for social support & 39.27 & 38.16 & 3.216 & $\mathrm{p} \leq 0.05$ \\
\hline The acceptance of responsibility & 25.23 & 28.55 & 0.479 & \\
\hline Escape-avoidance & 23.7 & 38.35 & 2.845 & $\mathrm{p} \leq 0.05$ \\
\hline Planning of problem solving & 39.64 & 38.57 & 3.652 & $\mathrm{p} \leq 0.05$ \\
\hline Positive revaluation & 36.12 & 30.89 & 2.165 & $\mathrm{p} \leq 0.05$ \\
\hline
\end{tabular}


The strategy of confrontation assumes that morally unstable students have a pronounced preference for coping confrontation - this indicates that these students may have impulsivity in behavior (sometimes with elements of hostility and conflict), hostility, and unjustified perseverance. For moral students, this strategy of confrontation indicates that it provides the ability of the individual to resist difficulties, energy and enterprise in solving problem situations, the ability to defend their own interests, and cope with anxiety in stressful conditions.

The distancing strategy assumes that moral students can reduce the subjective significance of difficult situations and prevent intense emotional reactions to frustration. Morally unstable students are likely to devalue their own experiences, underestimate the significance and possibilities of effective overcoming of problematic situations.

The strategy of self-control assumes trying to overcome negative experiences. Moral students may have a tendency to hide their feelings and motivations in connection with a problematic situation from others. Morally unstable students have the ability to avoid emotiogenic impulsive actions, the predominance of a rational approach to problem situations.

The strategy of searching social support assumes attempts to solve the problem by attracting external (social) resources. Moral students search mainly informational support, which involves searching recommendations from experts and acquaintances who, from the respondent's point of view, have the necessary knowledge. Morally unstable students are looking for mostly effective support, which leads to the need for help with specific actions.

The strategy of accepting responsibility assumes a position of moderate use of this strategy in moral students, which reflects the individual's desire to understand the relationship between their own actions and their consequences, the willingness to analyze their behavior, and look for the causes of actual difficulties in personal shortcomings and mistakes. For morally unstable students, it can lead to unjustified self-criticism, feelings of guilt and dissatisfaction with themselves. These features are known to be a risk factor for the development of depressive states.

The escape-avoidance strategy assumes that morally unstable students have a clear prereading of the avoidance strategy, which indicates non-constructive behaviors in stressful situations: denial or complete disregard of the problem, evasion of responsibility, etc. Moral students have the ability to quickly reduce emotional stress in a stressful situation.

The strategy of planning a solution to the problem assumes that moral students can purposefully and systematically resolve the problem situation. Morally unstable students are likely to have excessive rationality, lack of emotionality, intuitiveness, and spontaneity in their behavior.

The strategy of positive revaluation assumes that moral students can positively rethink the problem situation. Morally unstable students are likely to underestimate the individual's ability to effectively resolve a problem situation.

Table 3 shows the average indicators that characterize the moral orientation of consciousness and coping strategies of students' personality. The average values of students' coping strategies show that they act as coping strategies such as "confrontation" $(45.5 \%)$, "self-control" (45.34\%), and "planning of problem solving" (39.64).

Then we analyzed the results obtained using the method "Methods for diagnosing moral characteristics of the individual and the level of its psycho-ethical development" (A.V. Sukhih, N. I. Korytchenkova)

During the study, students were asked to evaluate each other's moral qualities such as: "self-criticism","justice", "sincerity", "truthfulness", "politeness", "sensitivity", "honesty", "self-love". The result of quantitative analysis of the obtained data is shown in figure 1. 


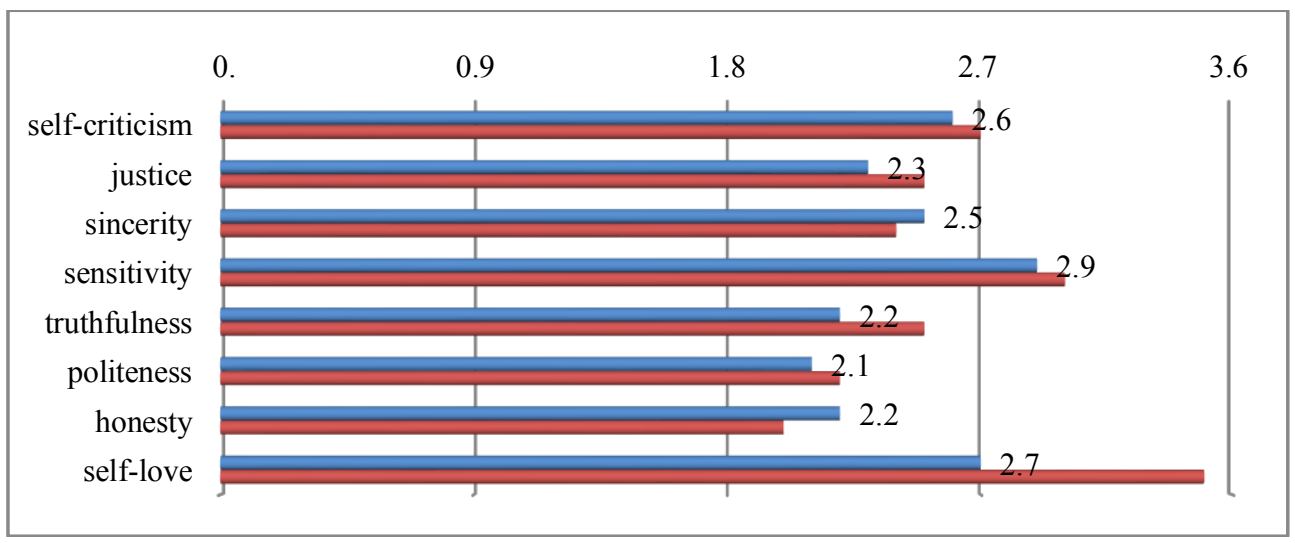

Fig. 1. Average values of indicators of moral characteristics of students' personality.

Quantitative analysis of the obtained data has shown that students' indicators of moral qualities are expressed at low levels, i.e. their assessed qualities are formed and manifest almost always.

Ranking by the degree of expression of moral qualities in students-specialists showed that the most pronounced "sensitivity", "self-love", and less pronounced "self-criticism", "sincerity", "justice", "truthfulness", "honesty" and "politeness".

Ranking by the degree of expression of moral qualities in students of master's degree showed that the most pronounced "self-love", "sensitivity", "self-criticism", and less pronounced "politeness", "truthfulness", "justice", "sincerity" and "honesty". Further, a qualitative analysis of the nature of the expression of each of the qualities of the moral sphere of students was carried out.

\section{Discussion}

50 students of the experimental group (20\%) have developed moral and ethical qualities at a high level, i.e. moral and ethical qualities are manifested as follows:

Sensitivity. It is characterized by sensitivity, responsiveness, caring for people around you in any circumstances, readiness to help in any situation and help out a friend in trouble.

Self-love. Students sometimes show a quality that expresses personal self-esteem, selfaffirmation, and dignity.

Self-criticism. Students are characterized by increased demands on themselves, the ability to correctly assess themselves and their capabilities, soberly evaluate themselves and admit their mistakes.

150 respondents $(60 \%)$ showed an average level of development of moral qualities, i.e. the listed components of moral development are also mandatory for students, but in some cases there may be minor changes, for example, there may be high self-esteem, deliberate lies to avoid trouble, they may not always come to the rescue, in some cases they may not be true.

Justice. Students are almost always fair. Very rarely they can show a lack of understanding of the other. Most likely, they are aware of their mistakes and strive to correct them.

Sincerity. Students are characterized by sincerity, openness, naturalness in behavior and expression of emotions, attitude to people around them, the desire for sincerity in relationships with close people, most often with people in the immediate environment. 
Truthfulness. Students are characterized by truthfulness and a negative attitude to lies, but not everyone can tell the whole truth themselves or hide it, but they can tell it to a direct question.

50 respondents $(20 \%)$ showed a low level of development of moral qualities, i.e. these students show a tendency to elevate themselves and overestimate their capabilities, a tendency to discuss and condemn the shortcomings of others, deceit, lack of concern for others, lack of a sense of tact, rudeness.

Polite. These students show disrespect for others. Politeness is a personality trait for them. Characterized by a lack of tact, rudeness.

Honesty. Respondents tend to be principled, which is almost always manifested, tend to discuss and condemn the shortcomings of others, deceit.

\section{Conclusions}

Summing up the results of an experimental study of the moral sphere of students' personality, we can make the following generalizing conclusions.

The higher the level of morality of a student, the less sociable and sociable they are. They are more characteristic of coping strategies, such as "confrontation", when there is an opportunity to actively confront difficulties and stressful effects, and "self-control", when students have a desire to hide their experiences and motivations from others in connection with a problem situation, which indicates a fear of self-disclosure, excessive demands on themselves, leading to over-control of behavior, there is also the possibility of avoiding emotiogenic impulsive actions, the predominance of a rational approach to problem situations. To a lesser extent, there is a coping strategy "planning of problem solving", when the student gradually learns the possibility of purposeful and planned resolution of the problem situation.

Mostly moral students are not satisfied with their life in the present, but at the same time they give full meaning and focus on the future, their choice fell on the following life-meaning orientations: "process of life", "life result". They are aimed at assessing the passed segment of life, a sense of how productive and meaningful was the lived part of it, which can speak of comprehension and reasonableness, they have already understood "how to live", "why" and "where to go", the past in their opinion can give meaning to the rest of life.

At the same time, students are morally unstable - they feel more satisfied with life, are more purposeful in the process of living it, can set new, interesting goals, and are able to control their life. They are hedonists who live in the present day. The more pronounced the negative moral orientation in the moral sphere, the higher the immorality of the students' personality. In general, student demonstrates an average level of moral consciousness, which is not critical for life in society.

\section{References}

1. N. Melnik, V. Kudriavtseva, Y. Tsiplakova, E. Ivanova, The European Proceedings of Social \& Behavioural Sciences. EpSBS. SCTCMG 2019. International Scientific Conference «Social and Cultural Transformations in the Context of Modern Globalism», 1857 - 1864 https://doi.org/10.15405/epsbs.2019.12.04.249

2. Yan Wang, Guosen Wang, Qiuju Chen, Lin Li, Consciousness and Cognition 56, 188198 (2017) https://doi.org/10.1016/j.concog.2017.09.007

3. J. Shepherd, Hedonism about the value within consciousness https://doi.org/10.4324/9781315396347-9 
4. N. Kostruba, Psycholinguistic Analysis https://doi.org/10.31470/2309-1797-2020-27-1164-180

5. A. Linchenko, SSRN Electronic Journal https://dx.doi.org/10.2139/ssrn.2554937

6. M. Manolov, Psychology 10, 1077-1094 (2019) doi: 10.4236/psych.2019.108070

7. M.B. Revushkina, Bulletin of Tomsk State University. Philosophy. Sociology. Political science 2(30), 145-153 (2015)

8. I. Nikolaeva, R. Ovcharova, Proceedings of the Ecological-Socio-Economic Systems: Models of Competition and Cooperation (ESES 2019) (2020) DOI https://doi.org/10.2991/assehr.k.200113.101

9. N. Yachina, Procedia - Social and Behavioral Sciences 19725, 1575-1579 (2015) https://doi.org/10.1016/j.sbspro.2015.07.113

10. R. Ara, T. Mahjabeen, Bangladesh Journal of Bioethics 1(3), 58-62 https://doi.org/10.3329/bioethics.v1i3.9636

11. I.E. Sokolovskaya, Bulletin of the Moscow State Regional University. Series: Philosophical Sciences 2, 119-125 (2019) DOI: 10.18384/2310-7227-2019-2-119-125

12. E.A. Petrova, N.N. Akimova, A.V. Romanova, I.E. Sokolovskaya, The Education and science journal 22(2), 98-120 (2020) https://doi.org/10.17853/1994-5639-2020-2-98120

13. V.B. Salakhova, I.E. Sokolovskaya, I.V. Ulyanova, O.V. Karina, A.I. Terekhova, Práxis Educacional 15(34), 683-694 (2019) https://doi.org/10.22481/praxisedu.v15i34.5805

14. A. Denisa Manea, Procedia - Social and Behavioral Sciences 1495, 518-523 (2014) doi: 10.1016/j.sbspro.2014.08.203.

15. T. Lindhard, Proceedings of DIALOGO-CONF (2017) DOI: $10.18638 /$ dialogo.2017.4.1

16. E. Can Aybek, D. Çavdar, T. Mutlu Nilüfer Özabac, Procedia - Social and Behavioral Sciences 1912, 2740-2746 (2015) doi: 10.1016/j.sbspro.2015.04.666

17. N. Khon, A. Kim, Procedia - Social and Behavioral Sciences 23614, 260-264 (2016) doi: 10.1016/j.sbspro.2016.12.025

18. O. Scott Curry, M. Jones Chesters, C.J. Van Lissa, Journal of Research in Personality 78, 106-124 (2019) https://doi.org/10.1016/j.jrp.2018.10.008

19. M.V. Zhizhina, Psychological-Educational Studies 10(4), 1-14 (2018) doi: 10.17759/ psyedu.2018100401

20. A. Spirina, Trends In The Development Of Science And Education (2018) doi: 10.18411/lj-08-2018-25

21. E. Sagone, M. Elvira De Caroli, American Journal of Educational Research 2(7), 463471 (2014) doi: 10.12691/education-2-7-5

22. A.V. Sukhih, N. I. Korytchenkova, Bulletin of Kemerovo State University 3, 1-3 (2009) DOI: $10.21603 / 2078-8975$ 